\title{
Impacto da externalização de serviços secundários em uma instituição de ensino superior
}

\author{
Bruno Alves dos Santos \\ Administrador - Gestão para Inovação e Liderança \\ Unisinos \\ bruno.santos@intelimed.com.br

\section{Carlos Alberto Diehl} \\ Doutor em Engenharia de Produção - Controle \\ Estratégico de Custos \\ Professor do PPG em Ciências Contábeis da \\ Unisinos \\ cd@unisinos.br
}

\author{
Rosane de Fátima Andrioli \\ Mestre em Ciências Contábeis pela Universidade do \\ Vale do Rio do Sinos - UNISINOS \\ Professora da Faculdade São Judas Tadeu em Porto \\ Alegre \\ rosane.andrioli@fiergs.org.br
}

Contextus

ISSNe 2178-9258

ISSN 1678-2089

Organização: Comitê Científico Interinstitucional Editor Científico: Marcelle Colares Oliveira Avaliação: Double Blind Review pelo SEER/OJS Revisão: Gramatical, normativa e de formatação Recebimento: 22/11/2009 Aprovação: 16/10/2012

\section{RESUMO:}

Este artigo objetiva investigar a implantação da externalização de determinados processos em uma IES particular do Sul do Brasil. Mediante estudo de caso, verifica-se o processo de externalização executado pela IES. São utilizadas entrevistas semiestruturadas, com três gestores que participaram dos processos de externalização, e pesquisa documental para a coleta de evidências. A investigação contemplou três atividades: alimentação, manutenção e limpeza e segurança. As duas primeiras passaram por processos de externalização distintos e a terceira mantém-se executada internamente. Os resultados apontam que na atividade de alimentação houve problemas no processo de externalização, com impacto negativo para os clientes, enquanto na de manutenção e limpeza há vantagens de custo e desempenho. Quanto à segurança, a IES entende que, em função do potencial impacto negativo para os alunos e pela dificuldade em encontrar um fornecedor de serviços condizente, o recomendável é a manutenção da atividade internamente.

Palavras-chave: Estratégia. Decisão. Externalização. Terceirização. Instituição de Ensino Superior (IES).

\section{ABSTRACT:}

This article aims to investigate the externalization of certain processes in a particular IES of southern Brazil. Through a case study, one verifies the externalization process adopted. It was used semi-structured interviews with three managers who have participated in the externalization process and information retrieval for collection of evidence. The investigation included three activities: feeding, cleaning and maintenance and safety. The first two went through different processes of externalization and the third is still performed internally. The results show that in the feeding activity there were problems in the externalization process, with negative impact to the customers, while in maintenance and cleaning there are advantages in cost and performance. Regarding safety, the IES believes that because of the potential negative impact to the students and the difficulty in finding a consistent service provider, it is recommended to execute internally activity.

Keywords: Strategy. Decision. Externalization. Outsourcing. Higher Education Institution (IES). 


\section{INTRODUÇÃO}

A externalização é uma prática que vem sendo incorporada por muitas empresas nas últimas décadas. A sofisticação dos serviços e das tecnologias oferecidas tem atraído empresas a incluírem cada vez mais atividades nos seus escopos de contratação, no intuito de redução de seus custos e melhoria do desempenho das atividades. Para Tayauova (2012), a externalização é uma das mais efetivas técnicas gerenciais atualmente utilizadas. Mesmo na área pública, a prática tem sido adotada (por exemplo, ALCANTARA, 2000). Por outro lado, ainda existem empresas mais comedidas no escopo de suas externalizações, seja pelo receio de perder o controle de seus processos seja pela dificuldade de trocar de fornecedor posteriormente ou, ainda, pela capacidade própria para realizar suas atividades (ANDRIOLI, 2009). Essas empresas, mesmo optando pela externalização fazem, muitas vezes, o caminho inverso e retornam às suas atividades internalizadas.

Diversas companhias ao redor do mundo têm terceirizado parte de seus processos que outrora foram produzidos ou distribuídos internamente. Segundo pesquisa realizada em 2007 pelo Instituto Brasileiro de geografia e Estatística (IBGE) no Brasil, os serviços terceirizados representam $48 \%$ dos novos postos de trabalho com carteira assinada.

A decisão entre externalizar ou manter a responsabilidade de atividades realizadas pela própria empresa pode estar entre as mais importantes no cenário competitivo, por envolver, entre outras variáveis, custos, os quais devem ser cuidadosamente analisados em razão do impacto que causam nos resultados da empresa (ANDRIOLI, 2009).

Existem alguns propósitos básicos para aqueles que decidem terceirizar: a diluição dos custos diretos e indiretos; a melhora do grau de eficiência de uma atividade; a manutenção de um nível mínimo aceitável de identificação com a empresa por parte dos novos executores das atividades terceirizadas. Para Sá et al. (1997), a terceirização cresce em importância no momento que a necessidade de melhor alocação dos recursos aumenta, surgindo a necessidade de redefinir operações com vista a funcionar de maneira mais enxuta e flexível. Assim sendo, a terceirização acaba se apresentando, em determinadas situações, como um dos instrumentos de mudança na busca por auxílio à restruturação organizacional para um melhor desempenho.

Externalizar operações é uma decisão que envolve variáveis que necessitam ser bem avaliadas para que a decisão possa ser tomada da maneira mais acertada possível. Essas variáveis têm características e pesos diferentes a serem considerados, conforme a situação em que a empresa se encontra. Algumas dessas variáveis são de cunho mais objetivo, como o aumento ou a diminuição dos custos. O custo foi a variável mais utilizada por gerentes para a tomada de decisão pela externalização nas últimas décadas. Com isso, muitas vezes, variáveis importantes e que podem ser determinantes para o fracasso ou o sucesso - como a qualidade do serviço e a capacidade do parceiro em cumprir as atividades - foram relegadas a segundo plano. Em uma Instituição de Ensino Superior (IES), essas questões estão muito presentes. Se, por um lado, o crescimento da competição na área, pelo aumento do número de concorrentes (aumento de $73 \%$ do número de IES privadas entre 2001 e 2010, Instituto Nacional de Estudos e Pesquisas Educacionais (Inep), 2012), exige um desempenho melhor, por outro, é necessário avaliar o impacto de eventuais externalizações sobre a percepção dos principais usuários, os alunos. Assim, a questão de estudo desta pesquisa é: como se desenvolve o processo de implantação da externalização de atividades em uma IES?

Este estudo tem como objetivo investigar a implantação da externalização de determinados processos em uma instituição de ensino particular do Sul do Brasil. Por tratar-se de IES, pode-se caracterizá-la como prestadora de serviços. A pesquisa desenvolve-se em meio a incertezas decorrentes das diversas visões sobre o processo de decisão entre o "fazer" e o "comprar" e na busca do entendimento sobre a externalização como uma alternativa estratégica vantajosa para algumas empresas e desvantajosa para outras (ANDRIOLI, 2009).

$\mathrm{O}$ artigo estrutura-se em seis etapas principais. A primeira traz a revisão bibliográfica sobre temas relacionados à externalização, à estratégia e à decisão. Nas etapas seguintes, apresentam-se a metodologia, a análise do 
caso, a análise dos dados e a conclusão.

\section{UMA VISÃO ESTRATÉGICA PARA A DECISÃO PELA EXTERNALIZAÇÃO EM EMPRESA PRESTADORA DE SERVIÇOS}

\subsection{Externalização}

De acordo com Bergamaschi (2004), a externalização é uma prática utilizada há muito tempo, desde os séculos XVIII e XIX, e vem se tornando cada vez mais comum. Algumas atividades empresariais são transferidas para empresas ou pessoas externas à organização, que podem fazê-las de forma melhor.

Baily et al. (2000) mencionam que, nos anos 1980 e 1990, as privatizações das atividades do setor público obrigaram as organizações a submeterem seus serviços de limpeza e de alimentação aos rigores do ambiente competitivo, resultando na contratação de muitos desses serviços em empresas privadas. A questão básica levantada pelos autores foi relativa às vantagens econômicas no desempenho dos serviços por um terceiro ou pela própria empresa. No entendimento desses autores, a externalização logística proporciona serviços mais econômicos.

Na linguagem empresarial brasileira, tem-se conhecimento de que o termo terceirização ou externalização foi integrado na década de 1980, quando o processo de transferência de serviços que eram realizados pelas próprias empresas foi ganhando espaço nas organizações (PIRES, 2004; RAMALHO, 2007).

Com relação às terminologias utilizadas para a externalização, Marcelino (2007) escreve que há duas tendências visíveis na bibliografia sobre terceirização no que diz respeito à definição: a redução ou a ampliação do alcance do conceito. Na França, por exemplo, dá-se o nome de terceirização (sous-traitance) a um processo bem específico: é chamada terceirização apenas a situação em que há uma empresa subcontratada trabalhando dentro da empresa principal; se o trabalho for realizado fora, passa-se a chamar o processo de externalização (externalisation).
Essa distinção entre processos não é feita no Brasil e a terceirização é considerada como uma forma de externalização. Adota-se como definição abrangente para a externalização o processo de contratação de trabalhadores por empresa interposta, ou seja, a relação em que o trabalho é realizado por uma empresa, mas contratado por outra (MARCELINO, 2007). Portanto, por uma questão prática e de uniformização de linguagem, adota-se, nesta pesquisa, a terminologia "externalização". Quanto ao conceito, a externalização pode ser entendida como uma abordagem de gestão que permite delegar a um agente externo a responsabilidade por processos, atividades ou serviços até então realizados pela empresa, configurando um relacionamento colaborativo e interdependente entre contratante e contratado (PIRES, 2004).

Diante da complexidade do tema, as empresas, de forma geral, têm visão parcial acerca das vantagens e dos riscos da externalização. Dessa forma, como contribuição teórica, no Quadro 1 apresentam-se algumas vantagens e desvantagens da prática, identificadas a partir de revisão bibliográfica.

\section{Quadro 1 - Vantagens e desvantagens da externalização logística}

\begin{tabular}{|c|c|c|}
\hline Autores & Vantagens & Desvantagens \\
\hline $\begin{array}{l}\text { Baily et al. } \\
(2000)\end{array}$ & $\begin{array}{l}\text { Serviços logísticos mais } \\
\text { econômicos. }\end{array}$ & \\
\hline $\begin{array}{l}\text { Ballou } \\
\text { (1993; } \\
2001)\end{array}$ & $\begin{array}{l}\text { Custo reduzido e menor } \\
\text { capital exigido; acesso à } \\
\text { tecnologia e às habilidades } \\
\text { gerenciais; serviço ao } \\
\text { cliente melhorado; } \\
\text { vantagem competitiva por } \\
\text { aumento de penetração no } \\
\text { mercado; aumento do } \\
\text { acesso a informações para } \\
\text { o planejamento; riscos e } \\
\text { incertezas reduzidas. }\end{array}$ & $\begin{array}{l}\text { Perda do controle sobre } \\
\text { atividades críticas } \\
\text { logísticas que podem } \\
\text { resultar em vantagens } \\
\text { potenciais não realizadas. }\end{array}$ \\
\hline $\begin{array}{l}\text { Porter } \\
\text { (1986) }\end{array}$ & $\begin{array}{l}\text { Redução dos custos fixos } \\
\text { e da alavancagem; } \\
\text { incorporação dos } \\
\text { habilidades } \\
\text { fornecedores/canais } \\
\text { externos; abertura de } \\
\text { acesso às pesquisas e } \\
\text { know-how de outros } \\
\text { fornecedores/canais; } \\
\text { incentivos estimulantes à } \\
\text { negociação entre as partes; } \\
\text { menor investimento em } \\
\text { capitais; menores custos } \\
\text { para superar as barreiras } \\
\text { de mobilidade; menores } \\
\text { barreiras de saída. }\end{array}$ & $\begin{array}{l}\text { Aumento potencial nos } \\
\text { custos futuros nas } \\
\text { transações correntes para o } \\
\text { externalizador relativas à } \\
\text { evolução do poder de } \\
\text { negociação entre as partes; } \\
\text { dificuldade em dispersar as } \\
\text { compras entre vários } \\
\text { fornecedores; dificuldade } \\
\text { em impor padronização de } \\
\text { especificações e serviços, } \\
\text { sujeitos a ofertas } \\
\text { diferenciadas; possibilidade } \\
\text { de implantação de fatores } \\
\text { que provocam custos de } \\
\text { mudanças por parte do } \\
\text { fornecedor principal; } \\
\text { diminuição do poder de } \\
\text { barganha pelo abandono da }\end{array}$ \\
\hline
\end{tabular}




\begin{tabular}{|c|c|c|}
\hline & & $\begin{array}{l}\text { possibilidade de produzir } \\
\text { internamente; aumento da } \\
\text { concentração na indústria } \\
\text { fornecedora (pressões por } \\
\text { maiores preços); aumento } \\
\text { da demanda para a } \\
\text { indústria fornecedora, } \\
\text { levando ao desinteresse em } \\
\text { colaborar nos requisitos de } \\
\text { qualidade e atendimento da } \\
\text { empresa compradora; } \\
\text { perdas de economia pela } \\
\text { combinação das operações } \\
\text { derivadas do controle e da } \\
\text { coordenação interna, de } \\
\text { informações, por evitar o } \\
\text { mercado, derivadas de } \\
\text { relacionamentos estáveis } \\
\text { entre as partes integrantes; } \\
\text { redução das possibilidades } \\
\text { de aprofundamento } \\
\text { tecnológico entre as partes; } \\
\text { diminuição da habilidade } \\
\text { de diferenciar; perda da } \\
\text { manutenção do controle } \\
\text { sobre o conhecimento } \\
\text { potencial. }\end{array}$ \\
\hline $\begin{array}{l}\text { Souza; } \\
\text { Bacic } \\
(2000)\end{array}$ & $\begin{array}{l}\text { Redução dos custos fixos; } \\
\text { possibilidade de } \\
\text { concentração de esforços } \\
\text { dentro do próprio negócio; } \\
\text { ampliação da capacidade } \\
\text { produtiva da empresa. }\end{array}$ & $\begin{array}{l}\text { Custos de desconfiança e } \\
\text { de insegurança. }\end{array}$ \\
\hline $\begin{array}{l}\text { Pires } \\
(2004)\end{array}$ & $\begin{array}{l}\text { Redução de custos fixos e } \\
\text { redução e racionalização } \\
\text { da estrutura organizacional } \\
\text { interna; possibilidade de } \\
\text { concentrar esforços nas } \\
\text { atividades fim do negócio; } \\
\text { maximização dos retornos } \\
\text { sobre investimentos } \\
\text { internos mediante } \\
\text { concentração de } \\
\text { investimentos no que a } \\
\text { empresa desempenha } \\
\text { melhor; acesso a } \\
\text { determinada tecnologia, } \\
\text { minimizando } \\
\text { investimentos e } \\
\text { compartilhamento de } \\
\text { riscos com fornecedores. }\end{array}$ & $\begin{array}{l}\text { Inexistência de } \\
\text { fornecedores adequados; } \\
\text { fortes resistências internas } \\
\text { à mudança; problema com } \\
\text { a legislação trabalhista e } \\
\text { com sindicatos; } \\
\text { mensuração inadequada } \\
\text { dos custos de } \\
\text { externalização; perda de } \\
\text { controle sobre o processo e } \\
\text { criação de potenciais } \\
\text { competidores; dependência } \\
\text { de fornecedores; perda da } \\
\text { credibilidade e problemas } \\
\text { com a imagem da empresa, } \\
\text { no caso de uma eventual } \\
\text { falha de qualidade do } \\
\text { fornecedor. }\end{array}$ \\
\hline $\begin{array}{l}\text { Mintzberg } \\
\text { e Quinn } \\
\text { (2001) }\end{array}$ & & $\begin{array}{l}\text { Perda e habilidades críticas } \\
\text { ou o desenvolvimento de } \\
\text { habilidades erradas; perda } \\
\text { de habilidades funcionais } \\
\text { cruzadas; perda de controle } \\
\text { sobre os fornecedores. }\end{array}$ \\
\hline $\begin{array}{l}\text { Tayauouva } \\
\text { (2012) }\end{array}$ & $\begin{array}{l}\text { Foco nas competências } \\
\text { centrais; redução de } \\
\text { custos; acesso a } \\
\text { experiências; melhoria de } \\
\text { desempenho e } \\
\text { flexibilidade. }\end{array}$ & $\begin{array}{l}\text { Perda do controle de } \\
\text { operações; ameaça à } \\
\text { segurança e } \\
\text { confidencialidade; } \\
\text { problemas de qualidade, } \\
\text { custos ocultos e realocação } \\
\text { de pessoas. }\end{array}$ \\
\hline $\begin{array}{l}\text { Kurdi et al. } \\
\text { (2011) }\end{array}$ & $\begin{array}{l}\text { Maior foco na missão; } \\
\text { redução de custos } \\
\text { operacionais; melhora na } \\
\text { posição competitiva. }\end{array}$ & $\begin{array}{l}\text { Ameaça à segurança e } \\
\text { confidencialidade de } \\
\text { informações; aumento de } \\
\text { custos ocultos (custos } \\
\text { legais de contratação, entre } \\
\text { outros); dedicação não- } \\
\text { exclusiva. }\end{array}$ \\
\hline
\end{tabular}

Fonte: Adaptado dos autores pesquisados.
O conhecimento dessas questões é crucial, pois a decisão pela externalização pode tornar-se uma medida estratégica, principalmente quando empresas competem por preços, qualidade e ampliação de mercado, em que qualquer processo manuseado de forma ineficaz ou inadequada, que não objetive a maximização de resultados, pode comprometer a competitividade (CHOPRA; MEINDL, 2004). Essas afirmações confirmam a necessidade de serem considerados, em caso de decisão pela externalização, tanto os fatores econômicos como também os fatores estratégicos, tema da próxima seção.

\subsection{Estratégia}

Estratégia é uma palavra que vem do grego strategos e está intimamente relacionada com a questão militar. Strategos significa "um general em comando de um exército". No mundo empresarial, somente no final da década de 1940 é que foi dado início ao tratamento do conceito de estratégia pela literatura (OLIVEIRA; KUYVEN, 2004).

Na década de 1950, quando a resposta a descontinuidades ambientais começou a tornar-se importante, o conceito de estratégia passou a fazer parte do vocabulário das empresas. Nos primeiros tempos, a palavra estava muito associada ao sentido militar, e era definida como a ciência e a arte do emprego das forças na guerra (ANSOFF; McDONNELL, 1993).

O estudo da estratégia no meio acadêmico tem origem na formação dos grupos de pesquisa sobre história de negócios, fundados em 1927 na Harvard Business School, nos Estados Unidos. Mas é a partir dos anos 50, com os trabalhos de Alfred Chandler Jr. e Igor Ansoff, que se alcança maior consistência no corpo teórico da administração estratégica em comparação àquela que fora estruturada até então (JEREMY, 2002). De acordo com Certo et al. (2005, p. 3), define-se administração estratégica como “[...] um processo contínuo e interativo que visa manter uma organização como um conjunto integrado a seu ambiente".

Sobre estratégia, pode-se mencionar Simon (1979), que a entende como um conjunto de decisões que determinam o comportamento a ser exigido em determinados períodos 
de tempo. Mintzberg (1995) complementa, definindo estratégia como uma forma de pensar no futuro, integrada no processo decisório, com base em um procedimento formalizado e articulador de resultados e em uma programação. Assim, pode-se dizer que as estratégias devem indicar o rumo futuro (caminho), mediante regras formalizadas (conjunto de decisões), em estruturas flexíveis (articuladas), permitindo mudanças rápidas no rumo definido anteriormente (ciclo em movimento).

Porter (1989) afirma que a estratégia para o alcance de vantagem competitiva está relacionada ao posicionamento para enfrentar as cinco forças competitivas, que são: novos entrantes potenciais no mercado, fornecedores, produtos substitutos, compradores e concorrentes. Ao enfrentar essas cinco forças, as empresas deparam-se com três abordagens estratégicas para superar as demais: liderança no custo total, diferenciação e enfoque (em custo ou em diferenciação). As estratégias de liderança no custo e de diferenciação buscam a vantagem competitiva em um amplo espectro de segmentos, enquanto a estratégia de enfoque visa à vantagem de custo ou de diferenciação em segmento restrito.

De acordo com Porter (1989), a especificação da vantagem competitiva é a questão fundamental do plano estratégico, uma vez que ela estabelece o contexto para os planos funcionais nas diversas áreas. A vantagem competitiva depende de se conseguir uma ligação mais ampla que a dos concorrentes entre a disposição dos compradores para pagar e os custos.

Para Fleury e Fleury (2003), a empresa, ao formular uma estratégia competitiva, deve identificar e potencializar a competência essencial. A identificação dessas competências, que deve ser conduzida pela alta administração, apresenta-se como uma difícil tarefa. Em alguns casos, as empresas podem entender que são constituídas pelas atividades ou pelos processos que elas executam da melhor forma, priorizando o repasse daqueles que são problemáticos de ser desempenhados internamente, tratando a decisão de forma meramente operacional. Na maioria dos casos, a tarefa de identificação das competências essenciais é complexa. O erro na sua identificação pode conduzir a equívocos na tomada de decisão.

Outro entendimento, também importante, refere-se à gestão da estratégia. Ansoff e McDonnell (1993) entendem a gestão estratégica como uma prática potencialmente poderosa para lidar com as condições de mudança que cercam a empresa hoje em dia; mas é complexa e dispendiosa, apesar de compensadora. Os autores dizem, ainda, que ela oferece importante ajuda para lidar com a turbulência enfrentada pelas empresas; portanto, merece atenção como uma ferramenta de gestão não apenas para a empresa, mas também para uma ampla gama de organizações sociais.

Uma boa gestão estratégica pode ser fonte de vantagem competitiva para a organização. A vantagem competitiva (PORTER, 1989) não pode ser compreendida observando-se a empresa como um todo. A avaliação da empresa deve ser feita internamente, desmembrando as várias atividades ou funções e, externamente, mediante as várias interfaces com os agentes externos. A empresa ganha vantagem competitiva executando essas atividades estrategicamente importantes de uma forma mais barata ou de um modo melhor do que a concorrência (SHANK; GOVINDARAJAN, 1997), visando à otimização de recursos e resultados.

No caso de opção pela externalização de suas atividades, as organizações necessitam reestruturar-se para garantir uma maior integração e, consequentemente, aumentar suas vantagens competitivas (PORTER, 1989) em função não apenas do foco individual, mas da eficiência coletiva de toda a cadeia produtiva. O tipo de relacionamento estabelecido com parceiros externos influencia diretamente os ganhos da troca de experiência (TAYAUOVA, 2012).

Concluindo esta seção, percebe-se que não existe uma fórmula pronta e única que possa direcionar a decisão pela externalização ou internalização de atividades. Ela irá variar em termos de vantagens e desvantagens, dependendo da estratégia de cada empresa. No intuito de auxiliar na avaliação da decisão pela externalização, a próxima subseção abordará a teoria da decisão. 


\subsection{Teoria da decisão}

A teoria da decisão nasceu com Herbert Simon, que a utilizou como fundamento para explicar o comportamento humano nas organizações (SIMON, 1979). Tomar decisões é uma atividade crucial para as organizações e acontece todo o tempo, em todos os níveis, influenciando diretamente no seu desempenho, afetando a organização ou o próprio grupo. As atividades realizadas pelas empresas nos seus diversos níveis hierárquicos são essencialmente processos de tomada de decisão e resolução de problemas (SIMON, 1979). A importância dessa atividade pode ser percebida empiricamente e, ao analisar a organização, é difícil pensá-la sem considerar a ocorrência constante do processo decisório. Para decidir, é necessário identificar todas as alternativas possíveis, bem como suas consequências. Simon (1963) entende a tomada de decisão como sinônimo de administração e, ainda, como o processo de pensamento e ação que culminará em uma escolha. A escolha consiste em selecionar cursos alternativos de ação ou mesmo aceitar ou rejeitar uma ação específica.

Gomes, Gomes e Almeida (2002) mencionam que o processo decisório é a análise de um conjunto de alternativas de ação geralmente associadas a um conjunto de recursos e que concorrem para a solução de problemas previamente identificados. Seu objetivo é atender simultaneamente aos requisitos do mercado, aos requisitos internos da empresa e aos interesses dos acionistas e das demais partes interessadas, levando em consideração as variáveis quantitativas e qualitativas que permeiam o processo.

Simon (1963, p. 14) afirma que a decisão compreende três fases principais: "descobrir as ocasiões em que devam ser tomadas, identificar os possíveis cursos de ação e decidirse entre um deles". Essas três atividades consomem diversas etapas do tempo disponível dos executivos, trabalho esse que consiste não apenas em tomar decisões próprias, mas também em providenciar para que toda a organização que dirige, ou parte dela, tome-as também de maneira efetiva. "A maior parte das decisões pelas quais é responsável não são suas, mas sim de seus subordinados" (SIMON, 1963, p. 18).
O processo decisório é considerado um dos pontos centrais para o eficaz gerenciamento das organizações e configura-se como a principal atribuição dos gestores. Pode ser definido como o processo de pensamento e ação que culminará numa escolha, e seu eixo central é a definição do problema, a avaliação de alternativas e, finalmente, a decisão (ROCHA; MACIEL; SILVA, 2002). $\mathrm{O}$ estudo do processo decisório apresenta diferentes modelos e abordagens, não necessariamente excludentes entre si, mas complementares. Há métodos que retratam a multicriteriedade inerente ao processo de tomada de decisão. Entretanto nenhuma metodologia substitui a capacidade de decisão dos envolvidos no processo (GOMES; GOMES; ALMEIDA, 2002).

Na próxima seção, tratam-se as peculiaridades de gestão de empresas voltadas à prestação de serviços, que, a exemplo das particularidades dos demais segmentos, envolvem-se diariamente com situações que demandem decisões sobre melhores opções na prestação de seus serviços.

\subsection{Empresas de serviços: peculiares em sua gestão}

Gianesi e Corrêa (1996) afirmam que não é simples nem aconselhável classificar empresas como de manufatura ou de serviços. A diferenciação dos processos dá-se pela gestão de cada tipo de operação. Segundo Fitzsimmons e Fitzsimmons (2000), a distinção dos serviços acontece entre entradas e recursos. Para os serviços, as entradas são os próprios consumidores e os recursos são os bens facilitadores, o trabalho do funcionário e o capital sob o comando do gerente. $\mathrm{O}$ sistema de serviços interage com os clientes, que são os participantes do processo. Para Gianesi e Corrêa (1996), as principais características das operações de serviços são: a intangibilidade dos serviços; a necessidade da presença do cliente ou de um bem de sua propriedade; a produção e o consumo simultâneos de serviços; a capacidade perecível com o tempo.

A intangibilidade dos serviços está associada principalmente à vivência gerada pela utilização de serviços oferecidos pelas empresas aos clientes, ao contrário dos produtos, que podem ser possuídos. $\mathrm{Na}$ 
necessidade da presença do cliente ou de um bem de sua propriedade, o cliente é encarado como um elementochave no processo de serviços, pois é ele que, de certa forma, dispara a operação, influenciando também a maneira como o serviço acontece. A necessidade da presença do cliente faz com que a localização e os custos para o deslocamento dos possíveis clientes sejam levados em conta por eles na escolha do serviço. Em um processo orientado para serviços, a mão de obra é extremamente importante devido à proximidade do cliente com os funcionários.

Por causa da produção e do consumo simultâneo, os serviços normalmente não apresentam processo intermediário entre a produção e o consumo. Essa característica acarreta a impossibilidade de realizarse estoque de serviços, o que determina também a impossibilidade de efetivar-se um isolamento do sistema em relação às variações do ambiente externo. De uma maneira direta, empresas de serviços estão muito mais vulneráveis às variações do ambiente.

Essa característica também cria uma dificuldade muito grande para que os gerentes possam estimar a capacidade produtiva da empresa e aperfeiçoar seus processos. Como o serviço não pode ser estocado, também a capacidade produtiva colocada disponível que não for utilizada (pela inexistência de demanda) é perdida. A situação contrária, em que a demanda do cliente não é atendida, também pode prejudicar a empresa. Tendo em vista que para se prestar um serviço o cliente necessita estar vivenciando aquele evento de uma maneira bastante intensa, o não atendimento da demanda pode mudar drasticamente a percepção do cliente, tornando-a negativa.

A característica da capacidade perecível com o tempo faz com que as capacidades de atendimento não usadas sejam perdidas. Como exemplo, uma poltrona de avião vazia, hotéis sem clientes, hospitais sem pacientes e instituições de ensino sem alunos. Em todos esses casos o serviço está disponível, porém a falta de demanda naquele período faz com que ele seja perdido para sempre.

\subsection{Estratégia de externalização}

Aspectos apontados pelos autores nas seções anteriores demonstram a complexidade que envolve a tomada de decisão pela externalização. Essa complexidade esteve escondida pela aparente eficiência da externalização, que apresenta, em princípio, vantagens em relação à redução de custos fixos. Em curto prazo, essas variáveis podem ser consideradas satisfatórias para se proceder à externalização. Para Souza e Bacic (2000), entretanto, essas vantagens concretizam-se unicamente em empresas nas quais a decisão pela externalização baseia-se em uma visão de longo prazo, com perspectiva estratégica e de integração, de fato, do fornecedor externalizado ao sistema empresarial.

Para Pochman (2007), o Brasil apresenta características peculiares em relação à externalização, o que ocorre principalmente pelo ambiente econômico de semiestagnação que caracteriza o país. Por conta dessa situação, a externalização no Brasil foi muito aplicada como uma estratégia de gestão defensiva, sendo utilizada para a simples redução de custos associada à sobrevivência das empresas. Essa situação, portanto, difere muito do caso Toyota, em que a externalização propiciou a melhoria dos processos, acarretando rentabilidade, possibilidade de expansão e ganho de competitividade. Essa estratégia de sobrevivência pode ter feito com que muitas empresas se precipitassem na hora de decidir pelo "fazer ou comprar", realizando um processo de externalização de maneira imponderada ou equivocada.

Souza e Bacic (2000) recomendam a utilização de fatores quantitativos e qualitativos, quando da decisão pela externalização. Mesmo que os dados qualitativos sejam de difícil mensuração, eles devem ser considerados em decorrência de sua importância no apoio à decisão.

De acordo com Corrêa e Caon (2002), as decisões entre "fazer ou comprar" eram tomadas basicamente levandose em conta conceitos de custos marginais. Se o custo marginal de executar a atividade fosse menor que o custo marginal de externalizar a atividade, o mais adequado seria produzir internamente. Para o autor, somente a partir dos anos 1990 passou a haver preocupação em relação a precauções mais estratégicas em detrimento apenas de 
considerações envolvendo os custos marginais. Uma das preocupações deveria ser em relação às competências centrais das atividades a serem externalizadas.

Hamel e Prahalad (1995, p. 233) definem competência como "[...] um conjunto de habilidades e tecnologias, e não uma única habilidade ou tecnologia isolada". Ainda, segundo os autores, as competências essenciais são, de forma mais básica, uma fonte de vantagem competitiva, e em relação à externalização é necessário que novos parceiros de negócios e prestadores de serviços estejam profundamente integrados e cientes do trabalho a ser realizado, para que eventualmente as competências da empresa não sejam desfeitas. Essa ideia é reforçada por Pochman (2007), que menciona o fato de que, em uma visão de longo prazo, ao invés de privilegiar apenas resultados imediatos, a externalização possa trazer maiores benefícios às empresas.

Pochman (2007) diferencia a externalização em dois tipos. Cada um desses tipos corresponde a características diferentes na contratação de mão de obra e na forma como ela é empregada. O primeiro tipo refere-se às atividades externas (secundárias) ao processo produtivo. Em geral, pode-se definir como a externalização-base, concentrada na atividade-meio do interior do circuito da produção de bens e serviços. As empresas que exercem essas funções não são, necessariamente, parceiras que mantêm contratos formais de longo prazo, pois atendem atividades importantes, porém não essenciais ao funcionamento do conjunto da cadeia de produção. Esse tipo de externalização responde mais a atividades periféricas do processo produtivo, mais especificamente a tarefas como segurança, transporte, alimentação, manutenção, limpeza, asseio e conservação.

O segundo tipo refere-se às atividades internas (primárias) ao processo produtivo. Na maior parte das vezes, podese identificar como superexternalização da mão de obra, caracterizada por atividade-fim do interior do circuito da produção de bens e serviços. Por conta disso, as empresas que exercem essas funções são geralmente parceiras que possuem contratos formais de longo prazo, atendendo atividades essenciais ao funcionamento da cadeia de produção.
De acordo com Pochmann (2007), no segundo tipo, o alinhamento das empresas parceiras tende a ser maior que na externalização-base, envolvendo uma série de requisitos de competição, como integração na cadeia de produção, qualidade, prazos, produtividade e outros. Para o sucesso da operação, torna-se extremamente necessária a integração total das parceiras em relação às tecnologias e ao modo operante, estando inclusos também a necessidade de capacitação e o monitoramento dos processos.

Conclui-se aqui o referencial necessário ao embasamento deste estudo. A seguir apresenta-se a metodologia utilizada para o desenvolvimento do trabalho.

\section{METODOLOGIA}

A metodologia utilizada nesta pesquisa foi o estudo de caso descritivo. Por meio de uma investigação empírica em uma IES localizada na região Sul do Brasil, mostrase o processo de externalização empregado. O escopo da pesquisa foram as áreas de limpeza e manutenção, alimentação e segurança.

A coleta de evidências focou-se em elementos qualitativos com entrevistas em profundidade, utilizando-se roteiros semiestruturados com os gestores participantes do processo para a externalização de atividades. Também se usou pesquisa documental. Inicialmente foi feita uma entrevista com o gestor de Recursos Humanos da IES. A entrevista possibilitou o entendimento do processo da tomada de decisão que envolveu a externalização em relação à forma como é feita a gestão dos terceiros que prestam serviços para a IES. Com base nessa entrevista, buscou-se contato com o profissional responsável direto pela gestão dos contratos relacionados à empresa que presta serviço de limpeza e manutenção. Esses dois profissionais, além de terem participado do processo de externalização, são responsáveis pela gestão dos contratos e das estratégias de atuação da IES com os parceiros.

Um terceiro gestor, o gerente de infraestrutura da IES, foi entrevistado, investigando-se outra perspectiva em relação ao processo decisório de externalização das atividades. Embora não lide atualmente com os parceiros, esse gestor foi participante do processo decisório na 
externalização de algumas atividades dentro da IES.

Utilizou-se a pesquisa institucional do ano de 2006 como ferramenta para avaliar a percepção do público frequentador da IES em relação às três áreas externalizadas e abordadas neste trabalho. Esta pesquisa abrange o aspecto de satisfação de alunos, professores e funcionários em relação aos serviços prestados no campus da IES: transporte, jardinagem, alimentação, bancos correios, entre outros.

A análise foi realizada de forma qualitativa com a interpretação dos dados coletados, a fim de constatar convergências e divergências entre eles e propor alternativas de melhorias. $\mathrm{O}$ estudo teve algumas limitações, como a falta de acesso a alguns gestores também participantes do processo de decisão e a alguns dados quantitativos considerados sigilosos pela IES. Não foi objetivo deste trabalho avaliar as relações contratuais entre as empresas, mas, sim, avaliar as circunstâncias em que os processos foram terceirizados.

\section{ANÁLISE DE CASO}

A IES em análise é uma universidade de cunho confessional, localizada no Sul do Brasil e possui mais de 20 mil alunos e dois mil empregados, entre professores e funcionários administrativos. Tem várias décadas de atividade e mais de sessenta cursos de graduação e duas dezenas de cursos de pós-graduação stricto sensu, além de várias atividades de extensão e pós-graduação lato sensu. A referida IES solicitou não divulgar sua identidade nesta pesquisa.

Segundo o Gestor de Recursos Humanos da IES, em determinado momento a instituição passou a refletir sobre a possibilidade de "abandonar" determinadas atividades que eram geridas internamente, transferindo-as a terceiros. Com isso, seria possível voltar todas as energias para o ensino, o que teoricamente facilitaria a melhora nos serviços (cursos) oferecidos. Nesse momento, a IES assumiu a premissa de que o fato de passar algumas atividades a uma empresa prestadora de serviços poderia melhorar o custo-benefício dessas atividades. Em tese, a empresa contratada seria uma especialista em sua área, e poderia realizar o trabalho com mais eficiência do que vinha sendo realizado com funcionários diretamente contratados.

A instituição de ensino buscava diminuir os custos das operações periféricas, como alimentação, manutenção e limpeza, e, ainda, voltar-se estritamente para seu core business - sua competência essencial. A IES mantinha uma média salarial referente aos funcionários de suas atividades periféricas bem acima do mercado, o que tornava cara a operação. Outro aspecto considerado na hora de decidir pela externalização é que a gestão de determinadas atividades também ficavam prejudicadas pela falta de conhecimento e especialização necessária por parte da IES. Mediante tais circunstâncias, a instituição começou a buscar empresas em condições de assumir as atividades.

A partir do momento que se optou pela externalização, houve dois processos diferentes em relação às atividades investigadas neste trabalho. Em relação às áreas de alimentação do campus, o Gestor de Recursos Humanos da IES não considera a atual forma de gestão do processo como um processo de externalização, pois a instituição não contratou uma empresa para prestar o serviço, apenas desistiu da "exploração" do espaço. Essa desistência foi seguida de um processo de abertura de concorrência para empresas da área da alimentação que estivessem interessadas em "explorar" o espaço. A empresa vencedora da concorrência aluga o espaço, responsabilizando-se pelo pagamento de seu consumo de energia e outras despesas, tendo a possibilidade de montar o seu negócio mediante algumas regras contratuais. Essas regras não ficam muito claras para este trabalho, mas o gestor afirma que elas são relacionadas a preços e qualidade dos produtos. Esse estilo de prestação de serviços, ao invés de gerar custos para a IES, acaba gerando uma receita.

Há nesse ponto uma preocupação da IES com as especificações sanitárias. O gestor considera esse um ponto importante na exploração dos espaços de alimentação do campus. Para ele, caso ocorra um incidente com qualquer um dos treze estabelecimentos voltados à alimentação, esse evento teria impacto direto na imagem da IES. Em caso de uma intoxicação alimentar, por exemplo, a exposição primeira seria da instituição de ensino e 
não do restaurante contratado, estando aí o motivo de preocupação com as especificações sanitárias. Em razão disso, há um esforço da IES para colocar em contratos o cumprimento obrigatório de especificações sanitárias, a fim de evitar ocorrências imprevistas.

Um dos gestores participantes do processo de decisão pela externalização afirmou que o comportamento dos consumidores mudou após a contratação do prestador de serviços. Segundo ele, os consumidores passaram a buscar alternativas de alimentação, visto que os preços já não eram mais tão baixos do que quando geridos internamente, e a qualidade percebida relacionada a sabor, variedade e atendimento dos restaurantes também caíra.

A outra área-alvo de pesquisa deste trabalho, e que igualmente passou pelo processo de externalização, é a de manutenção e limpeza da IES, setor que passou por um processo de externalização bastante diferente do ocorrido na área de alimentação. Nesse caso, a IES procurou no mercado empresas que apresentassem o melhor plano para a atuação na instituição de ensino, ficando a empresa contratada responsável por todos os processos de limpeza e manutenção.

A busca por esse parceiro para realizar as atividades de manutenção e limpeza foi considerada, pelo gestor de recursos humanos, como importante elemento, na medida em que a empresa contratada estaria desenvolvendo um trabalho em nome da IES. Nesse caso, o gestor aponta uma interação muito maior entre a empresa contratante (IES) e a empresa contratada (responsável pela manutenção e limpeza).

Há, nessa circunstância, uma responsabilidade da instituição de ensino referente ao terceiro. Como exemplo disso, o gestor aponta o caso de reclamações trabalhistas que acontecem contra a empresa contratada por partes de seus funcionários. Quando a empresa que presta serviços à IES é acionada na justiça por algum de seus funcionários, a instituição de ensino também é notificada e é integrada ao processo, tendo corresponsabilidade nessa situação. Por esse motivo, o gestor defende o uso de muita pesquisa para escolher uma empresa que possa representar os interesses da IES com qualidade.
A empresa escolhida para realizar o trabalho de manutenção e limpeza precisa apresentar mensalmente todas as guias de pedidos de licenças e alvarás, a fim de provar que ela é capaz de suportar todas as questões formais e legais que envolvem a atividade. Aliado a isso, a IES busca no prestador de serviços uma excelência em seus serviços, o que nem sempre é percebido pelo público frequentador da IES de maneira objetiva, já que não ele não tem acesso aos números relativos à operação. Essa percepção está muito relacionada à forte rejeição que existiu na época em que a externalização foi efetivada, segundo opinião dos gestores.

Durante o processo de implantação, a IES enfrentou alguns problemas em relação à percepção das pessoas diante da externalização da limpeza e da manutenção. Como foi referido, o piso salarial dos postos de trabalho que a IES possuía para as funções de limpeza e manutenção era bastante elevado, o que acarretava muitos custos. Com a externalização, apesar de a empresa contratada ter incorporado diversos funcionários que eram da IES, esse piso salarial diminuiu consideravelmente em relação aos mesmos postos de trabalho, o que acabou gerando um desconforto em professores, funcionários e até mesmo alunos. Além disso, essa medida gera riscos legais, uma vez que os funcionários têm seus salários reduzidos para executar a mesma função.

Existe uma preocupação muito grande da IES em relação à imagem que os funcionários externalizados possam passar à comunidade. Em razão disso, conforme o gestor, todos os funcionários contratados pela empresa parceira para prestar o serviço de limpeza e manutenção dentro da IES passam por um período de treinamento e adaptação. Isso ocorre para que os funcionários possam habituar-se ao funcionamento da operação e para que eles possam integrar-se aos aspectos culturais da IES, a fim de evitar distorções da imagem da IES perante a sociedade.

Os responsáveis diretos pela gestão dos terceiros consideram que há uma integração entre as duas empresas. Segundo eles, os serviços tiveram um acréscimo considerável de qualidade em decorrência do nível de especialização do prestador de serviços, que contratou máquinas que facilitam o serviço, 
principalmente o de jardinagem. Apesar de os dados quantitativos - como compra de máquinas e número de cortes de grama - mostrarem uma melhoria nos processos, existem reclamações oriundas de alunos e professores relacionadas aos serviços prestados, que ainda não puderam ser melhorados.

A IES recebe todos os meses um relatório completo das atividades prestadas no campus, com diversos indicadores, entre outros: identificação dos gráficos de manutenções corretivas x preventivas; quantidade de manutenções preventivas especificadas por área; índices de acidentes; níveis de consumo de energia, de qualidade do paisagismo e de qualidade da limpeza; quantidade detalhada de manutenção preventiva e corretiva no mês. São evidências de que a empresa contratada disponibiliza uma gama de ferramentas de controle do andamento dos processos.

Conforme os gestores pesquisados, os controles feitos pela empresa atualmente contratada não eram viáveis quando a atividade era executada pela própria IES. Faltavam ferramentas e especialização para que se viabilizasse dessa forma.

De acordo com o gestor responsável pela administração do contrato de externalização, todos os indicadores operacionais apresentados foram montados em conjunto entre as duas empresas. Ambas as partes preocuparamse em montar uma operação que prioriza atividades de manutenção por meio de uma gestão próxima entre as duas empresas. No entanto, Tsai et al. (2012) alertam para o risco de altos custos de governança para especificar e monitorar a contratação de terceiros.

Após a externalização, os gestores entrevistados identificaram melhorias em diversas partes dos processos. Embora tenha havido variações na qualidade durante o primeiro ano de parceria, o constante contato entre as partes levou à discussão de melhorias e à consequente melhora nos processos. Os custos relativos às atividades de manutenção e limpeza diminuíram, visto que a IES não mais se obriga a manter profissionais próprios e que custavam caro, pagando simplesmente pelo cumprimento de um serviço e cobrando resultados por ele.
Outra atividade investigada pelo trabalho foi a de segurança. Buscou-se, por meio de entrevistas com os gestores, entender por que esse processo não foi externalizado como os demais (limpeza e manutenção, e alimentação, entre outros), especialmente se se considerar que ele também não está ligado à atividade-fim da IES.

De acordo com o Gestor de Recursos Humanos, diversos fatores influenciaram a não externalização da segurança do campus. Em primeiro lugar, a área de segurança é considerada estratégica à IES, visto que os agentes têm contato direto com os alunos e deparam-se com diversas situações delicadas. Por estarem representando a IES diante dos alunos no dia a dia, precisam ter um nível de abordagem e comportamento diferenciado. Eles são considerados pelo gestor como uma espécie de recepcionistas dentro do campus.

Também foi mencionado que o nível intelectual e de treinamento dos agentes necessita ser muito alto, visto que eles estão carregando diretamente a imagem da IES perante os alunos e de maneira muito próxima. Os gestores responsáveis pela decisão de não externalizar essa atividade, na época em que outras áreas da IES passaram pelo processo, consideraram não existir no mercado empresas de vigilância capazes de prestar um serviço que suprisse as necessidades da IES relacionadas à qualidade dos serviços.

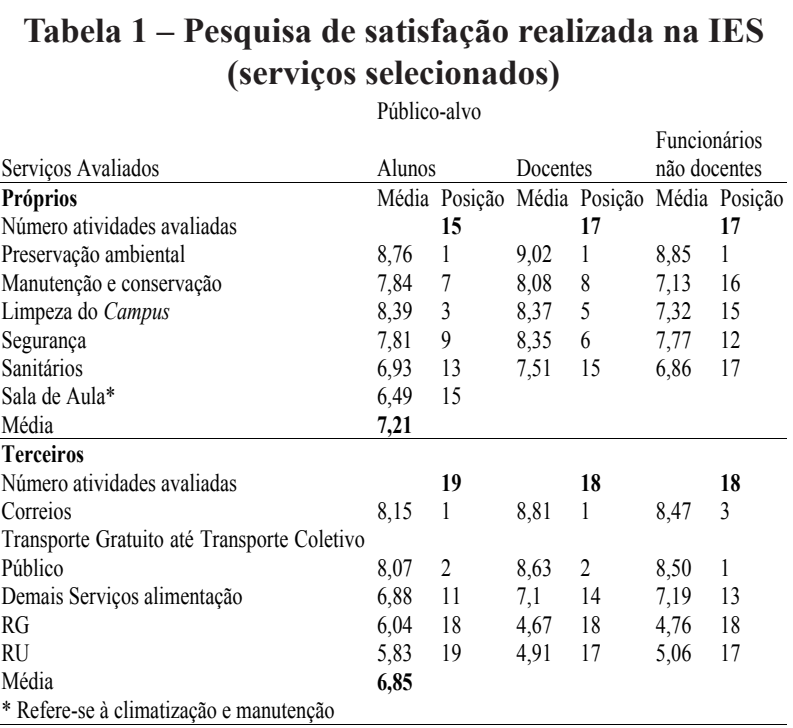

Fonte: Relatório sintético da pesquisa de avaliação da infraestrutura (2006-2). 
Acessou-se o relatório de pesquisa feita pela IES, a fim de conhecer e avaliar o grau de satisfação dos públicos usuários da infraestrutura disponibilizada por meio de seus serviços e produtos do campus gerenciados internamente ou por terceiros. Esse relatório é fruto de um estudo quantitativo com aplicação de questionário via web. A amostra de alunos foi de 2.484, além de 134 professores e 145 funcionários. O relatório mostra a percepção do público em relação às três áreas avaliadas pelo trabalho. Foi usada uma escala de 1 a 10 para os serviços prestados, sendo 10 a melhor pontuação e 1 a pior.

A Tabela 1 mostra parte dos serviços avaliados na pesquisa de satisfação citada. $\mathrm{O}$ que se percebe é que os serviços externalizados investigados neste artigo têm baixo grau de satisfação. Mesmo os serviços gerenciados pela IES, mas executados por terceiros, como a sala de aula e os sanitários, têm baixo nível de satisfação, com exceção da manutenção e conservação, em posição intermediária. Corroborando isso, os serviços gerenciados e executados por terceiros, como correios, transporte gratuito e os de alimentação, mostram menor grau de satisfação para com as atividades investigadas pelo presente trabalho.

Os gestores entrevistados afirmam que a IES não tem nenhuma intenção em internalizar os processos mencionados. Eles entendem que essa é a melhor opção para a instituição, e pretendem respeitar o planejamento feito. Todavia também entendem que o processo de externalização deve estar em constante melhoria.

\section{ANÁLISE DAS EVIDÊNCIAS}

A IES, objeto deste estudo, caracteriza-se como uma empresa prestadora de serviços. Em decorrência disso, apresenta algumas especificidades em relação a sua gestão. $\mathrm{O}$ cliente encontra-se muito próximo ao processo produtivo, tornando-se parte ativa dele. Dessa maneira, é necessário que se tenha um processo bastante alinhado e eficiente, a fim de manter a percepção do cliente positiva em relação aos serviços prestados.

O processo de externalização da IES começou, segundo os gestores entrevistados, na intenção de voltar a organização para sua competência central - o ensino, pois, para eles, aspectos como alimentação, segurança e manutenção e limpeza, apesar de importantes, são processos secundários. A externalização apareceu, nesse caso, como uma medida para levar a organização à redução de custos relacionados a atividades que não eram consideradas atividades-fim, sem perder qualidade. Dessa maneira, seria possível voltar todas as energias da IES ao aperfeiçoamento de sua atividade-fim. Essa posição é corroborada por Tayauova (2012), para quem a busca por focar nas atividades-fim é uma das vantagens da externalização. No entanto, Kurdi et al. (2011) alertam que podem ocorrer vantagens quando da externalização de atividades não relacionadas às atividades-fim. Como esses autores sugerem, as atividades de gestão de instalações podem ser consideradas, em geral, como não relacionadas às atividades-fim. Porém, no presente caso, as instalações têm influência direta na percepção dos clientes, o que pode afetar a execução da atividade-fim, o ensino.

A externalização ocorreu de maneiras distintas. O processo relacionado às atividades de alimentação apresenta característica de sublocação do espaço, visto que não há um pagamento pelos serviços prestados. Nesse caso, é gerada uma receita, já que as empresas pagam para explorar o espaço comercial. Embora a IES tenha em contrato as especificações de operação relacionadas a preço e qualidade, não há interação entre o tomador e o prestador de serviços, aspecto extremamente importante para garantir o sucesso da operação. A área de alimentação apresenta algumas peculiaridades. Dos diversos restaurantes, lanchonetes e cafés que se localizam no campus da IES, poucos são administrados pela mesma empresa. Existe mais de uma empresa que explora os espaços destinados à alimentação e isso acaba forçando a IES a lidar com diversas empresas diferentes, o que dificulta o alinhamento das estratégias dela às dos seus prestadores de serviços.

Entre os restaurantes administrados pela mesma empresa estão o Restaurante Universitário (RU) e o Restaurante Geral (RG). Esses dois são os estabelecimentos de maior vínculo com a imagem da IES. São os únicos que não possuem marca própria, apenas são conhecidos como Restaurante Universitário e Restaurante Geral, o que 
contribui para que sejam identificados como um serviço diretamente ligado à IES, piorando a visão dos usuários em relação a esse serviço. Ambos os estabelecimentos ficaram com as médias mais baixas da avaliação institucional para professores, alunos e funcionários. Em todos os públicos, eles aparecem em penúltimo e último lugar. Além disso, em paralelo com outras empresas, podem ser considerados como refeitórios funcionais, reforçando o vínculo com a IES.

Não é possível saber ao certo o que provoca essa insatisfação em relação ao RU e RG, mas preço e qualidade podem ter uma influência forte no nível de satisfação dos consumidores, já que um dos gestores entrevistados reconhece a perda de qualidade e o aumento do preço. No entanto, essa é uma das reconhecidas desvantagens potenciais da externalização (TAYAUOUVA, 2012). Outro aspecto pode estar ligado ao fato de que essa atividade foi recém-externalizada, mudando a relação dos usuários com ela, o que por si (a mudança) pode ter afetado o grau de satisfação com a prestação do serviço, conforme já esperava Pires (2004).

Diante desse problema, poderia haver uma investigação para tentar apurar as causas dessa insatisfação. Ao que parece, o modelo de externalização adotado nessa área não permite uma maior interação entre as partes, o que também pode estar dificultando o processo de alinhar objetivos, resolver problemas e, consequentemente, melhorar o nível dos serviços e a percepção dos usuários em relação a eles. É possível considerar o RU e o RG como um fator crítico e problemático do processo de externalização da IES. A empresa prestadora de serviços e a IES não estão suficientemente próximas e alinhadas para garantir a satisfação de seus clientes. Liou et al. (2011) afirmam que o processo de externalização é complexo e envolve uma série de fatores interdependentes, que devem ser considerados conjuntamente, o que não parece ter sido o caso. Os autores sugerem pelo menos quatro grandes categorias de critérios a considerar: compatibilidade, qualidade, custo e risco, que podem ainda ser subdivididos em onze subcritérios. Como os autores ainda observam, o peso, isto é, a importância de cada critério muda para cada situação analisada.
Os demais restaurantes da área de alimentação da IES também mantêm relação de locação com a IES. Os espaços são cedidos mediante o pagamento de aluguel $\mathrm{e}$ ocupam uma posição intermediária quanto à satisfação dos consumidores na avaliação institucional. Embora não possuam um serviço com alto grau de satisfação, podem estar mais bem posicionados por estarem desvinculados da IES e apresentar marca própria, o que afasta a imagem de vínculo com a IES. Além disso, tem existência de forma independente já há longo tempo, não tendo sofrido recente mudança de situação.

A externalização dos serviços de alimentação não se estrutura de acordo com os conceitos estudados. Faz-se necessária maior integração entre os restaurantes e a IES. Embora a externalização desse setor seja uma ação para cumprir metas estratégicas da IES, não parece que as empresas contratadas tenham consciência de quais são as intenções da contratante relativas aos serviços prestados por elas dentro do campus. Tayauova (2012) relatou problemas advindos da perda de controle gerencial de atividades, o que se assemelha à situação enfrentada pela IES.

A área de limpeza e manutenção da IES também passou por um processo de externalização, porém está mais bem estruturada, e seu processo difere bastante do processo ocorrido na área de alimentação. Nesse caso, a IES buscou alternativas, por meio de pesquisa no mercado, que pudessem suprir as necessidades da atividade. A empresa a ser contratada elaborou um plano específico para suprir as necessidades da área. Para Kurdi et al. (2011), a transferência da gestão de instalações para terceiros pode trazer maior retorno sobre investimento.

A IES e a empresa contratada possuem forte integração. Os gestores reconhecem a necessidade de estar próximo ao parceiro para que o serviço seja desempenhado de maneira satisfatória. Por estar cientes da necessidade de trabalhar em conjunto, os responsáveis pela gestão do contrato de externalização procuram estar próximos dos processos, entendendo aquilo que acontece no dia a dia e debatendo possíveis melhorias. Com a implantação da externalização e, em decorrência disso, com a melhoria do nível de profissionalização na execução das atividades, observam- 
se resultados positivos nos serviços de manutenção e limpeza, pois os gestores passaram a ter mais ferramentas para subsidiar e controlar o desempenho dos serviços. Como os gestores reconhecem essas atividades como atividades próprias externalizadas, ao invés de locação de espaços, como no caso da alimentação, eles se mostram mais atentos à prestação dos serviços. Isso pode ajudar a explicar o melhor alinhamento entre essas atividades e a IES em relação à atividade de alimentação. Conforme Souza e Bacic (2000) e Pochmann (2007), é fundamental para o sucesso da externalização a integração do terceiro ao sistema empresarial contratante. Essa é uma posição também reconhecida por Tayauova (2012), para quem a forte integração e o controle encontram sustentação na Resource-Based View (Visão Baseada em Recursos).

Em relação aos custos, o fato de a IES pagar por um pacote de serviço, ao invés de pagar por uma equipe, pode reduzir o custo da atividade. De acordo com os gestores, quando a manutenção e a limpeza eram desempenhadas por funcionários próprios, era necessário manter alguns profissionais com alto nível de formação e que custavam caro. Além disso, esses profissionais muitas vezes ficavam ociosos, já que a demanda pelos serviços prestados por eles não era constante. Pagava-se pela ociosidade. Conforme os gestores, houve redução nos custos das atividades externalizadas, corroborando o que afirmam diversos autores (BALLOU, 2003; PORTER, 1986, SOUZA; BACIC, 2000 e PIRES, 2004). Por razões de sigilo, a IES não permitiu a divulgação das economias obtidas.

A empresa parceira da IES mantém profissionais de alto nível que, entretanto, prestam serviços à IES e aos demais clientes do parceiro. Isso possibilita, de certa forma, que o custo desse profissional possa ser diluído entre todos os clientes do parceiro, tornando o serviço de menor custo. A mão de obra diretamente envolvida com os processos de limpeza e manutenção também caracteriza uma economia. Isso ocorre, segundo o gestor, porque a média salarial do funcionário contratado pela empresa externalizada é mais baixa do que a da equipe de manutenção e limpeza que a própria IES outrora possuía. Esse fato contribui para tornar o pagamento do serviço mais barato, o que torna desaconselhável a internalização do processo. Ainda, cabe mencionar que quando os processos eram internos os gestores ficavam sobrecarregados por gerenciar tarefas operacionais e tinham dificuldade de voltar-se para a gestão. A eficiência que a externalização trouxe por facilitar o dia a dia dos gestores não é percebida pelo público que frequenta a IES. Porém, há de se questionar aqui se o problema não se localizava mais no modelo de gestão em si - ou nos gestores - do que na própria atividade.

$\mathrm{Na}$ avaliação institucional, o desempenho da limpeza e manutenção não foi muito bom. Esses quesitos estão representados na pesquisa por limpeza do campus, manutenção e conservação do campus, sanitários e sala de aula. A limpeza do campus aparece bem colocada na pesquisa com os alunos, em terceiro lugar, com média 8,39 , e a manutenção e conservação do campus aparece em sétimo, com 7,84. O quesito sanitário diz respeito à limpeza dos aparelhos, e teve um grau de insatisfação bem alto, ficando entre as últimas posições na percepção de alunos, funcionários e professores. O quesito sala de aula foi avaliado somente pelos alunos e teve um desempenho ruim, posicionando-se em último lugar. Nesse quesito, as principais reclamações dos alunos foram em relação à manutenção dos equipamentos em sala de aula e à temperatura do ambiente. A primeira questão relacionase às atividades internalizadas, enquanto a segunda é característica da infraestrutura oferecida pela IES. A perda da qualidade e/ou do controle sobre as atividades são desvantagens citadas por alguns autores (PORTER, 1986, PIRES, 2004 e MINTZBERG; QUINN, 2001; TAYAUOVA, 2012). Para evitar isso, Sullivan (2005 apud KURDI et al., 2011) sugere focar na escolha das habilidades adequadas antes de focar em redução de custos de curto prazo.

A partir desses resultados, percebe-se a necessidade de discussão entre contratante e contratada para que os serviços sejam adequados e cheguem a um patamar satisfatório. É notável que os serviços externalizados que dizem respeito principalmente à limpeza não sejam satisfatórios na percepção do público frequentador da IES. Esse fato, com certeza, prejudica a avaliação de eficiência em relação à externalização. É necessário que as causas do fraco desempenho desses quesitos sejam 
investigadas e reparadas a fim de preservar a imagem da instituição. Para Tsai et al. (2012), a falta de comunicação e de metas compartilhadas podem levar a um fracasso nos relacionamentos com terceiros. Por outro lado, para os autores, comprometimento e confiança reduzem os riscos de falhas.

Em parte, a relativa satisfação de gestores com os resultados da externalização denota viés interno em relação ao impacto das atividades, minimizando a importância de considerar o efeito sobre o cliente, conforme recomendam Gianesi e Correa (1996) em relação aos processos de serviços, caracterizando uma visão limitada para uma prestadora de serviços.

Um aspecto adicional a ser considerado é a escolha de uma empresa única para as atividades de limpeza e manutenção. São atividades de natureza diferente e, ao visar um parceiro que execute ambas, a IES reduz em muito seu leque de opções de fornecedores. Isso pode levar a uma significativa perda do poder de barganha com esses fornecedores, como adverte Porter (1986), ou à aceitação de contratados que não sejam especialistas nas atividades, reduzindo potencialmente a eficiência e a qualidade dos serviços. Para Tayauova (2012), o acesso às capacidades especializadas pode ser uma das vantagens advindas da externalização, o que fica restrito no caso de se buscar um generalista.

Outra área avaliada pelo trabalho é a de segurança. Ela não foi externalizada em decorrência da falta de empresas que pudessem prestar um serviço de qualidade, segundo a IES. Isso demonstra que houve uma pesquisa antes de decidir pela externalização dos serviços e, diferentemente das outras duas áreas mencionadas no trabalho, foi entendido que seria prejudicial para a IES. Embora possa ser mais barata a contratação de um serviço de vigilância, esse setor é considerado delicado pela IES pela proximidade com os alunos. Dessa forma, o impacto de um serviço mal prestado, sem a gestão direta da IES, poderia afetar negativamente a instituição, oferecendo riscos à sua imagem, conforme salienta Pires (2004). A qualidade do setor foi razoável na avaliação institucional, ficando com nota média acima de sete. Embora as notas da área de segurança não tenham sido tão altas como as das outras áreas, os motivos apresentados pelos gestores para não externalizar são consistentes.

\section{CONCLUSÃO}

A IES trata o tema externalização com base em uma necessidade de mudança em sua estrutura organizacional. Os custos considerados pelas atividades periféricas como limpeza e manutenção, alimentação e segurança eram altos. Segundo os gestores, a instituição possuía empregados altamente qualificados para essas atividades, como engenheiros e paisagistas, com média salarial acima do mercado. Esses profissionais não tinham demanda de trabalho constante, o que tornava desinteressante a relação custo-benefício.

Além dos aspectos financeiros, que foram avaliados qualitativamente por este trabalho, a IES tinha a intenção de voltar-se apenas para seu core business. Nesse caso, a instituição entendeu que não possuía capacidade de profissionalizar as atividades de limpeza, manutenção e alimentação. Reconhecendo isso, optou pela externalização, buscando no mercado algumas empresas que pudessem suprir as atividades. Era intenção da IES que houvesse uma diminuição da burocracia, deixando seus gestores menos atarefados com atividades consideradas periféricas.

Os processos de externalização foram distintos. A área de alimentação passou por um processo de sublocação de espaços para empresas que desejassem explorar o potencial comercial do campus. Nesse caso, a gestão em parceria com as empresas contratadas ficou deficiente, visto que a relação que há entre as partes é simplesmente de locação, dificultando à IES o alinhamento da sua gestão com a das empresas responsáveis pela prestação dos serviços. O número elevado de empresas que exploram a área de alimentação do campus também prejudica o processo. Nesse sentido, Kurdi et al. (2011) apontam dois fatores-chave para o sucesso de externalizações: a correta escolha da estratégia de externalização e sua adequada implantação. Para os autores, a escolha deve ser por um fornecedor que tenha as habilidades necessárias, cujos serviços sejam entregues com confiabilidade, certeza, custos efetivos e no prazo. 
Outro ponto sensível é o processo de externalização em si, no caso de limpeza e manutenção. A absorção de parte da mão de obra da contratante pela contratada gera riscos trabalhistas e sindicais, segundo relata Pires (2004). Há forte divergência no âmbito da justiça quanto à legalidade da externalização ou terceirização, conforme aponta Leite (1995, p. 28); o autor opina que "[...] a terceirização, em princípio, continua sendo ilegal em nosso país". A IES deveria repensar o sistema de alimentação existente, principalmente no que diz respeito ao Restaurante Universitário (RU) e ao Restaurante Geral (RG). Os serviços de alimentação em geral não tiveram um bom desempenho na avaliação institucional, ocupando as últimas posições na opinião de professores, alunos e funcionários. É necessário que a instituição de ensino trabalhe com os restaurantes, as lanchonetes e os cafés os motivos que fazem o desempenho ser ruim em comparação com outros serviços. Também deveria entender mais profundamente o que o público frequentador da IES espera da área de alimentação. A partir do momento que houver entendimento do problema será necessária uma gestão bastante integrada e próxima para que se possam discutir soluções para um objetivo comum, alinhando objetivos e estratégias.

A área de manutenção e limpeza possui um processo de externalização diferente do de alimentação, sendo sua gestão feita de maneira integrada entre a instituição de ensino e a prestadora de serviços. Todavia, os resultados encontrados na avaliação institucional não são bons. É necessário adequar em conjunto os parâmetros do serviço que está sendo prestado. A insatisfação do público frequentador da IES mostra que os serviços não estão sendo bem prestados. É preciso aproveitar a integração entre as partes para rediscutir as diretrizes dos serviços e melhorar a percepção do público frequentador, visto que, sendo a IES uma empresa de serviços, as falhas na limpeza e manutenção do campus influenciam a opinião de seus usuários em relação à qualidade da própria IES. Nesse sentido, há, em um processo de externalização, risco de perda ou interceptação de informações provindas dos clientes (TSAI et al., 2012), com efeito negativo sobre a reputação do contratante.

Na decisão pela externalização, é importante conhecer os custos do processo, bem como a sua evolução, e também avaliar, por intermédio de pesquisa, a percepção dos usuários em relação aos serviços externalizados pela organização.

Finalizando, o trabalho contribui para que haja uma melhor compreensão das situações que envolveram o processo de externalização da IES, contendo diversas variáveis, tais como desenvolvimento de parcerias e alinhamento de objetivos e estratégias. A pesquisa também auxilia a compreensão da complexidade envolvida em uma decisão de externalizar ou não processos e, abre, ainda, espaços para futuras pesquisas em relação ao tema, comparando este estudo com outros realizados em empresas e setores diferentes e em outras atividades.

\section{REFERÊNCIAS}

ALCANTARA, C. M. Processo de terceirização na Secretaria Municipal de Saúde de Almirante Tamandaré, Paraná, Brasil. Cad. Saúde Pública, Rio de Janeiro, 16(3):871-873, jul.-set., 2000.

ANDRIOLI, R. F. Proposta de modelo flexível para apoio à decisão de externalização: uma aplicação em logística de transporte. 2009. Dissertação (Mestrado) Programa de Pós-Graduação em Ciências Contábeis, Universidade do Vale do Rio dos Sinos, São Leopoldo, 2009.

ANSOFF, I.; McDONNEL, E. Implantando a administração estratégica. São Paulo: Atlas, 1993.

BAILY, P.; FARMER, D.; JESSOP, D.; JONES, D. Compras: Princípios e administração. Trad. Ailton Bomfim Brandão. São Paulo: Atlas, 2000.

BALlOU, R. H. Logística empresarial. São Paulo: Atlas, 1993.

Gerenciamento da cadeia de

Suprimentos: Planejamento, organização e logística empresarial. Porto Alegre: Bookman, 2001.

BERGAMASCHI, S. Modelo de gestão da terceirização de tecnologia da informação: um estudo exploratório. 
2004. Tese (Doutorado). Universidade de São Paulo, São Paulo, 2004.

CERTO, S. C.; PETER, J. P.; MARCONDES, R. C.; CESAR, A. M. R. Administração estratégica: planejamento e implantação da estratégia. 2.ed. São Paulo: Pearson Prentice Hall, 2005.

CHOPRA, S.; MEINDL, P. Gerenciamento da cadeia de Suprimentos: estratégia, planejamento e operação. São Paulo: Pearson Prentice Hall 2004.

CORRÊA, H. L.; CAON, M. Gestão de serviços: Lucratividade por meio de operações e de satisfação dos clientes. São Paulo: Atlas, 2002. 479 p.

FITZSIMMONS, J. A.; FITZSIMMONS, Mona J. Administração de serviços: operações, estratégia e tecnologia de informação. 2. ed. Porto Alegre: Bookman, 2000.537 p.

FLEURY, A. C.; FLEURY, M. T. L. Estratégias competitivas e competências essenciais: perspectiva para a internacionalização. Revista Gestão \& Produção, v. 10, n. 2, p.129-144, 2003.

GIANESI, I. G. N; CORRÊA, H. L. Administração estratégica de serviços: operações para a satisfação do cliente. São Paulo: Atlas, 1996, 233 p.

GRANT, R. M. The resource-based theory of competitive advantage: implications for strategy formulation. California Management Review, p. 114-135, Spring 1991.

GOMES, L. F. A. M.; GOMES, C. F. S.; ALMEIDA, A. T. Tomada de decisão gerencial: enfoque multicritério. São Paulo: Atlas, 2002.

HAMEL, G.; PRAHALAD, C. K. Competindo pelo futuro: estratégias inovadoras para obter o controle de seu setor e criar os mercados de amanhã. Rio de Janeiro: Campus, 1995. 377 p.

IBGE - Instituto Brasileiro de Geografia e Estatística.
Disponível em <www.ibge.gov.br>. Acesso em: 9 out. 2012.

INEP - INSTITUTO NACIONAL DE ESTUDOS E PESQUISA. Resumo Técnico do censo da educação superior de 2010. Disponível em < http://download. inep.gov.br/educacao_superior/censo_superior/ resumo_tecnico/resumo_tecnico_censo_educacao_ superior_2010.pdf>. Acesso em: 13 out. 2012.

KURDI, M. K; ABDUL-THARIM, A. H.; JAFFAR, N. M. K. AZLI, M. S. SHUIB, M. N. AB-WAHID, A. M. Outsourcing in Facilities Management - A Literature Review. Procedia Engineering, v. 20, p. 445-457, jan. 2011.

LEITE, C. H. B. Aspectos jurídicos da terceirização. Síntese Trabalhista, n. 68, p. 17-30, fev. 1995.

LIOU, J. J. H.; WANG, H. S.; HSU, C. C.; YIN, S. L. A hybrid model for selection of an outsourcing provider. Applied Mathematical Modelling, v. 35, n. 10, p. 51215133, out. 2011.

MARCELINO, P. Afinal, o que é terceirização? Em busca de ferramentas de análise e de ação política. Pegada, v. 8, n. 2, p.55-71, 2007.

MINTZBERG, H. Crafting Strategy. In: Harvard Business Review Paperback. Boston, Harvard Business Review, 1995.

MINTZBERG H.; QUINN, J. B. O processo da estratégia. 3. ed. Porto Alegre: Bookman, 2001. 404 p.

JEREMY, D. J. Business history and strategy. In: PETTIGREW, A.; THOMAS, H.; WHITTINGTON, R. Handbbok of strategy and management. London: Sage, 2002. p. 436-460.

OLIVEIRA, L. C. P.; KUYVEN, Arlete. Formação de estratégias em pequenas empresas: um estudo de caso. XXIV Encontro Nacional de Engenharia de Produção. Florianópolis, SC, Brasil, 3 a 5 nov. 2004. 
PAIVA,E.L;CARVALHOJR., J.M;FENSTERSEINFER, J. E. Estratégia de produção e de operações. Porto Alegre: Bookman, 2004. 192 p.

PINTO, A. K; XAVIER, A. N. Manutenção: função estratégica. Rio de Janeiro: Qualitymark, 2001. 341 p.

PIRES, S. R. I. Gestão da cadeia de suprimentos: conceitos, estratégias, práticas e casos. São Paulo: Atlas, 2004.

POCHMAN, M. A Superterceirização dos contratos de trabalho. Universidade Estadual de Campinas: Campinas, abr. 2007. Pesquisa encomendada pelo Sindeepres.

PORTER, M. E. Estratégia competitiva. Rio de Janeiro: Campus, 1986.

SÁ, M. P. et al. Terceirização no processamento final das indústrias farmacêutica e veterinária. In: ENCONTRO ANUAL DA ANPAD, XXI, 1997. Angra dos Reis. Anais... Angra dos Reis: ANPAD, 1997. Produção industrial e de serviços. 1 CD_ROM.

RAMALHO, A. R. Terceirização da logística de distribuição: um estudo de caso da empresa Artecola Ltda. Trabalho de Conclusão de Curso de Especialização. Universidade do Vale do Rio dos Sinos, São Leopoldo, 2007.

ROCHA, C. H. M.; MACIEL, C. E. C.; SILVA, A. M. A decisão na universidade: o caso da UFMG. Revista Múltipla. Brasília, a. VII, v. 9, n. 13, dez. 2002.

SHANK, J. K; GOVINDARAJAN, V. A revolução dos custos. Rio de Janeiro: Campus, 1997.

SIMON, H. A. A capacidade de decisão e de liderança. Rio de Janeiro: Fundo de Cultura, 1963.

SIMON, H. A. Comportamento administrativo: estudo dos processos decisórios nas organizações administrativas. 3. ed. Rio de Janeiro: Fundação Getúlio Vargas, 1979.
SOUZA, M. C. A. F.; BACIC, M. J. Por que os programas de terceirização falham? Revista Enfoque Reflexão Contábil, DCC/Univ. Estadual Maringá, v. 19/2, p. 16$27,2000$.

TAYAUOVA, G. Advantages and disadvantages of outsourcing: analysis of outsourcing practices of Kazakhstan banks. Procedia - Social and Behavioral Sciences, v. 41, p. 188-195, jan. 2012.

TSAI, M. C.; LAI, K.; LLOYD, A. E.; LIN, H. J. The dark side of logistics outsourcing - Unraveling the potential risks leading to failed relationships. Transportation Research Part E, v. 48, n. 1, p. 178-189, jan. 2012. 